\section{Biofuel: microalgae cut the social and ecological costs}

SIR - Much of the discussion over biofuel production has focused on higher plants and the problems associated with their use, such as the loss of ecosystems or the driving up of food prices, as discussed in your Editorial 'Kill king corn' and News Feature 'The little shrub that could - maybe' (Nature 449, 637 and $652-655$; 2007). The use of microalgae, which need not displace food crops, has tended to be overlooked.

Mass algal cultivation has been used to produce pharmaceuticals for more than a decade, so the technology is well developed. Annual yields per unit area are an order of magnitude greater than those for higher plants. Conservative estimates of 30,000 50,000 litres of lipid per hectare per year compare with 1,300-2,400 litres per hectare per year reported for plants with a high oil yield, such as oil palm or jatropha.

Also, biomass production need not compete with food production for either land or water. Both marine and freshwater algae may be used, so either sea water or fresh water can serve as the basis of the culture medium. And as land-based algal culture systems don't depend on soil fertility, barren land can be used.

Spin-offs in the form of aquaculture would seem feasible, so local communities could benefit from the activity. And in the case of freshwater algae, energy can be recovered from anaerobic digestion of the non-lipid waste: methane produced by this process could supply the needs of the algal cultivation processes and desalination of sea water, or be used for ammonia synthesis.

The cost of biofuel production from algae has been estimated at $\$ 50$ or less per barrel (M. E. Huntley and D. G. Redalje Mit. Adapt. Strat. Glob. Ch. 12, 573-608; 2007), making it more than economic at current oil prices, without subsidies.

Peter J. le B. Williams

School of Ocean Sciences, College of Natural Sciences, Bangor University, Menai Bridge, Anglesey LL59 5AB, UK

\section{Biofuel: corn isn't the king of this growing domain}

SIR - We fully agree with your Editorial 'Kill king corn' (Nature 449, 637; 2007) that corn (maize) is not a good feedstock for biofuels for a host of environmental, economic and humanitarian reasons.

We also agree that a sustainable biofuels industry needs to rely on non-food crops, such as cellulose from switchgrass or poplar trees, jatropha and possibly corn stover (stalks). Further research and development is necessary before such feedstocks will

become commercially viable.

In the United States, neither the 51 cents per gallon tax allowance given to blenders who mix ethanol (the biofuel derived from corn) into their petrol, nor the 54 cents per gallon tariff on imported ethanol are defensible. The latter serves largely to keep low-cost Brazilian ethanol from sugar cane out of the country.

Unfortunately, the new Farm Bill currently moving through Congress looks almost certain to preserve the farm-subsidy system of direct payments based on a per-bushel price scale for corn and other major crops. Subsidies go mainly to large farm operations, as these produce the most bushels. Corn producers have been among the largest beneficiaries of these subsidies, which encourage overproduction and excessive use of nitrogen fertilizer, the main source of the very potent greenhouse gas nitrous oxide. A new report from the National Academy of Sciences, Water Implications of Biofuels Production in the United States, also warns: "If projected future increases in use of corn for ethanol production do occur, the increase in harm to water quality could be considerable."

The current system of farm subsidies should have been reformed long ago to reward sound environmental practices, set an income cap for those receiving government payments and provide insurance against weather-related disasters.

But rather than killing king corn, we would prefer to say that the emperor - corn-based ethanol - has no clothes.

\section{Ford Runge, Benjamin Senauer}

Department of Applied Economics, University of Minnesota, St Paul, Minnesota 55108, USA

\section{Research in the wild}

SIR - In publishing 'His daughter's DNA' (Nature 449, 772-776; 2007), Nature is contributing to an important trend of involving the public in human genetics investigations. Laypeople and advocacy groups are demanding a say in biomedical research by contributing towards its funding and coordination, and even to the development of therapies.

As befits the genomic age, this collective activity is altering interactions among patients, medical professionals and scientists. It is stimulating unlikely alliances among academia, private donors, commerce, patient networks, the media and the state. New forms of solidarity are emerging.

The story of this child and her committed scientist father illustrates the emergence of a new form of social solidarity, founded on genetics. We have become witnesses and participants in a genetics experiment the girl's problem and her father's are made into our problem. The rest of us need to pay close attention and offer feedback. Ine Van Hoyweghen, Bart Penders

Department of Health, Ethics and Society, Maastricht University, PO Box 616, 6200 MD, Maastricht, The Netherlands

\section{Kyoto: doing our best is no longer enough}

SIR - Gwyn Prins and Steve Rayner are effective in reiterating the Kyoto Protocol's flaws, in their Commentary 'Time to ditch Kyoto' (Nature 449, 973-975; 2007). But their language is unnecessarily negative and they do not deliver a clear, credible alternative.

The Kyoto Protocol is not enough to create the low-emissions transformation in the global economy that is required to tackle the climate problem successfully. But it is already resulting in low-carbon investment and emissions reduction, and is a step towards an effective global treaty. In focusing on the name and arguing that it should be ditched, the authors overlook the potential of a 'Kyoto phase 2' that builds on this approach.

Their call for investment in developing technologies as a cornerstone of our response is right, but it doesn't address the important question of how to achieve it. It takes 20 years for new technologies to get to market - time we do not have. What we need are tools (such as a cost for carbon through market incentives and emissions trading) that facilitate rapid uptake of existing clean technologies. Investment in low-carbon technologies and cap-and-trade measures are two sides of the same coin: to achieve one requires the other. The market is awash with investment funds - good policy is needed to unlock them.

Trying to build a new agreement from the ground up, or hoping for a bottom-up solution to emerge from a mix of domestic responses, simply risks yet another decade of delay, diplomatic wrangling and nationalistic plea bargains while the climate system moves towards catastrophic tipping points.

As Winston Churchill said: "It's not enough that we do our best; sometimes we have to do what's required." That will also hold at the meetings in Bali next month, in Poland next year and in Copenhagen at the 2009 United Nations conference. Pointing out the treaty's inadequacies is all very well, but the harder and more vital job is building on it to achieve a more effective and adequate one.

Barry W. Brook ${ }^{\star}$, Nick Rowley ${ }^{*}$ Research Institute for Climate Change and

Sustainability, University of Adelaide,

South Australia 5005, Australia

†Kinesis, 255 Riley Street, Sydney,

NSW 2000, Australia

†Copenhagen Climate Council, and

Division of Environmental and Life Sciences,

Macquarie University, NSW 2109, Australia 